\title{
Digital Scanning and Non-destructive Techniques for Size Recovering and Rehabilitating the Structural Performance of Traditional Stuccoes
}

\author{
Rodica-Mariana $\operatorname{Ion}^{1,2(\bowtie)}(\mathbb{D})$, Valentin $\operatorname{Gurgu}^{3}(\mathbb{D}$, \\ Ioan Alin Bucurica ${ }^{3}$ (D), Sofia Teodorescu ${ }^{3}$ (D), \\ Ioana Daniela Dulama ${ }^{3}$ (D), Raluca Maria Stirbescu ${ }^{3}$ (D), \\ and Anca Gheboianu ${ }^{3}$ (D) \\ ${ }^{1}$ National Institute of Research and Development for Chemistry \\ and Petrochemistry - ICECHIM, 202 Splaiul Independentei, \\ 060021 Bucharest, Romania \\ rodica_ion2000@yahoo.co.uk \\ 2 Faculty of Materials Engineering and Mechanics, \\ Valahia University of Targoviste, 13 Sinaia Alley, 130004 Targoviste, Romania \\ 3 Institute of Multidisciplinary Research for Science and Technology, \\ Valahia University of Targoviste, 13 Sinaia Aleea, 130004 Targoviste, Romania
}

\begin{abstract}
Nowadays, there is a lack of knowledge regarding the traditional construction technology used in many of some important monuments in Romania. To address this limitation and to assist in their conservation and restoration, this study documents the existing condition of different historic structures. Methods and applications for 3D scanning, image scanning and nocontact and non-destructive methods are applied in this paper for structural analysis of the stuccoes from a patrimony building (Fântaneanu House, Slatina). To record and document the condition of this house, the laser scanning is used in order to identify the initial size and shape of some damaged parts of the monument. Advancement in diagnosis methods (spectral and microscopic analytical methods) for the conservation/restoration of this patrimony building.
\end{abstract}

Keywords: Patrimony $\cdot$ Stucco $\cdot 3 \mathrm{D}$ scanning

\section{Introduction}

In conservation and restoration procedures applied to different monuments from cultural heritage, is absolutely necessary to obey some rules, as follows:

- selection and characterization of historical materials (stones, mortars, bricks, plasters, pigments, binders, concrete, plastics);

- preparation of model substrates;

- simulation of their degradation in the presence of different external agents;

- in situ assessment of the materials (destructive and non-destructive testing); 
- identification of the cleaning materials and protective coatings;

- application and characterization of new materials correlated with environmental impact study, strengthening frescoes and basoreliefs with various consolidants;

- developing a methodology for testing the effectiveness of consolidation [1].

Known from more than 15 years, the three-dimensional scanning (3D scanning) method is a process that uses a contact or non-contact digitizing probe to capture the objects form and recreate them in a virtual workspace through a very dense network of points (xyz) as a 3D graph representation. There are known two types of 3D scanning, as follows: contact mode, which refers to the mechanical contact of the surfaces, and non-contact mode (without mechanical contact) which use optical sources, laser or a combination of the reproduction of the scanned surface. The best equipment is the 3D contact scanner, based on the controlled direction of the laser beam, followed by a measuring the distance of each point, the shape of objects, buildings and landscapes. The laser beam is that it can penetrate even the smallest cracks of the surface [2].

Materials that can be scanned with laser include: stone, ceramics, glass, metal, wood, plastic, rubber and clay. The tracks are measured by laser 3D scanning then they are compared to the projected model (CAD file) using a specialized software.

Methods and applications of 3D scanning method with image scanning correlated with non-contact and non-destructive investigation methods are applied in this paper for structural analysis of the stuccoes from a patrimony building (Fântaneanu House, Slatina). The laser scanning is used in order to identify the initial size and shape of some damaged parts of the monument, and some analytical methods (FTIR, SEM-EDS, MO) have been used for the diagnosis of this patrimony building.

\section{Experimental Part}

The used equipment is EXAscan Portable 3D Laser Scanner is a Mobile 3D Laser scanner, Portable 3D Metrology equipment, Creaform Exascan.

It could scan pieces of different sizes, with different geometries: 25,000 measurements/s, resolution of $0.2 \mathrm{~mm}$, accuracy of up to $0.040 \mathrm{~mm}$ (0.0016 in.), depth of field: $\pm 150 \mathrm{~mm}$ ( $\pm 6 \mathrm{in}$.), volumetric accuracy (with MaxSHOT 3D) of minimum $0.020 \mathrm{~mm}+0.025 \mathrm{~mm} / \mathrm{m}(0.0008 \mathrm{in} .+0.0003 \mathrm{in} . / \mathrm{ft}$, VXelements software, Catia V5, V6, 3D X-Element CD software, portable 3D Laser Scanner.

\subsection{Scan the Object}

After the parameterization, the object to be scanned is placed at the center of the reference points and the scan operation takes place, which involves scanning the surface of the object with the laser on the scanner. The result of the operation is a cloud of points. The program analyzes the points and joins them, so the final result being the scanned object in electronic format (digitized). 


\subsection{Analytical Investigation Equipment}

Fourier transformed infrared spectroscopy (ATR-FTIR) has been recorded with a Vertex 80 spectrometer (Bruker Optik GMBH, Germania) in the range of 4000$400 \mathrm{~cm}^{-1}$, equipped with DRIFT accessory.

The optical microscopy was performed with a Novex trinocular microscope (at different magnifications) and by a Primo Star ZEISS optical microscope that offers the possibility to investigate the samples in transmitted light at a magnification between $4 \mathrm{X}$ and 100X. The equipment had attached a digital video camera (Axiocam 105) which, by the microscope software, allowed real-time data acquisition.

The Scanning Electron Microscopy with Energy Dispersive Spectroscopy (SEMEDS) results were obtained by a SU-70 (Hitachi, Japan) microscope, used for characterization of micro- and nanomaterials qualitative and quantitative analysis of samples and composition of the structure for a sample surface, respectively.

\subsection{Samples}

The prelevated samples have been taken firstly for 3D scanning (Fig. 1) and secondly for analytical investigation (Fig. 2).

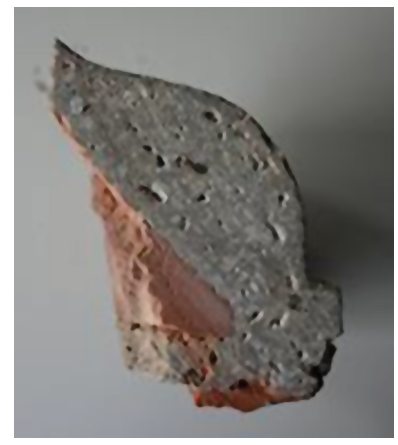

Fig. 1. The aspect of the stucco sample

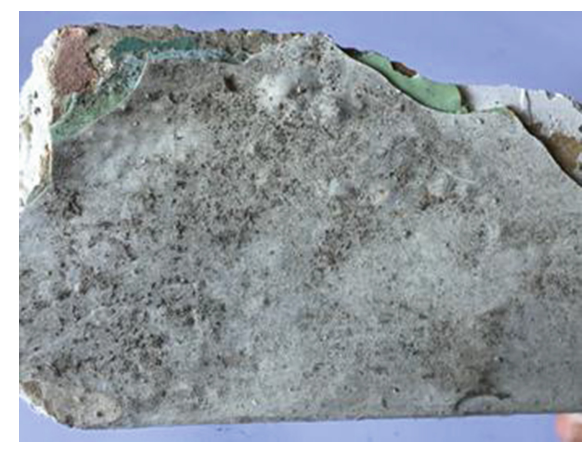

Fig. 2. The multilayer conserved stucco

\section{Results and Discussion}

\subsection{Scan the Object and Results Processing}

After the parametrization, the object to be scanned was placed at the center of the reference points and the scan operation takes place, which involves scanning the surface of the object with the scanner laser [3]. A network of points was obtained. The program allowed joining the points and a scanned object in electronic format (digitized) has been obtained. The processing was done using the "Digitized Shape Editor" module in the Catia program. A series of operations were performed to remove unusable surfaces and for the symmetrical reconstruction the mirroring operation was 
applied. After the scanner was configured, the reference points were scanned. They have the role of keeping the scanned object in a fixed position in $3 \mathrm{D}$ space $[4,5]$. The next step involved parameterizing the scanning procedure, namely choosing the resolution, optimizing the dot network, optimizing the limits, optimizing the precision, automatically filling the holes and removing the isolated surfaces. The file containing the digitized object was saved and processed in the CATIA program [5]. A series of operations were performed to remove unusable surfaces and for the symmetrical reconstruction the mirroring operation was applied, Fig. 3.

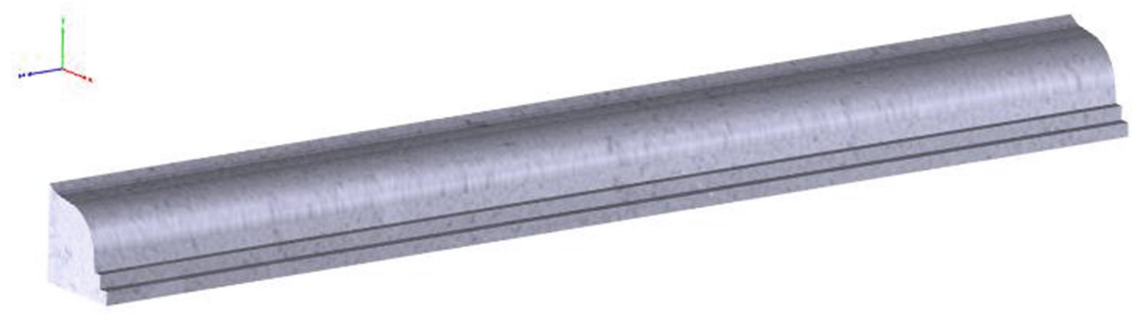

Fig. 3. The aspect of the stucco after 3D scanning

As could be observed, this program analyzes the points and joins them, so the final result being the scanned object in electronic format (digitized), by "Digitized Shape Editor" module in the Catia program [6, 7]. The not useful surfaces have been removed and for the symmetrical reconstruction the mirroring operation was applied.

After digitalization a detailed examination and investigation have been applied by using different multidisciplinary techniques applied for identification of the structure, composition and morphology of different heritage samples [8, 9], as follows: Scanning Electron Microscopy with Energy Dispersive Spectroscopy (SEM-EDS), Optical microscopy and Fourier Transformed Infrared spectroscopy (FTIR), only mentioning few of them.

By scanning electron microscopy was possible to identify 7 successive layers of various compositions, Fig. 4.

From the SEM investigations of the whole sample, some results have been obtained: seven layers of various materials, some of the layers without a perfect connection to each other due to the incompatibility of materials or degradation induced by the passage of time and the action of external agents: moisture, freeze-thaw, light or even improper restoration operations with negative effects. These data could be correlated with other chemical techniques, for example FTIR.

The FTIR spectral data of the MIR-region of the stucco's layers samples show only little variation and generally a high absorbance (strong signal) at wavenumbers between 500 and $1500 \mathrm{~cm}^{-1}$. This region of the spectrum is characteristic for $\mathrm{CO}$ 


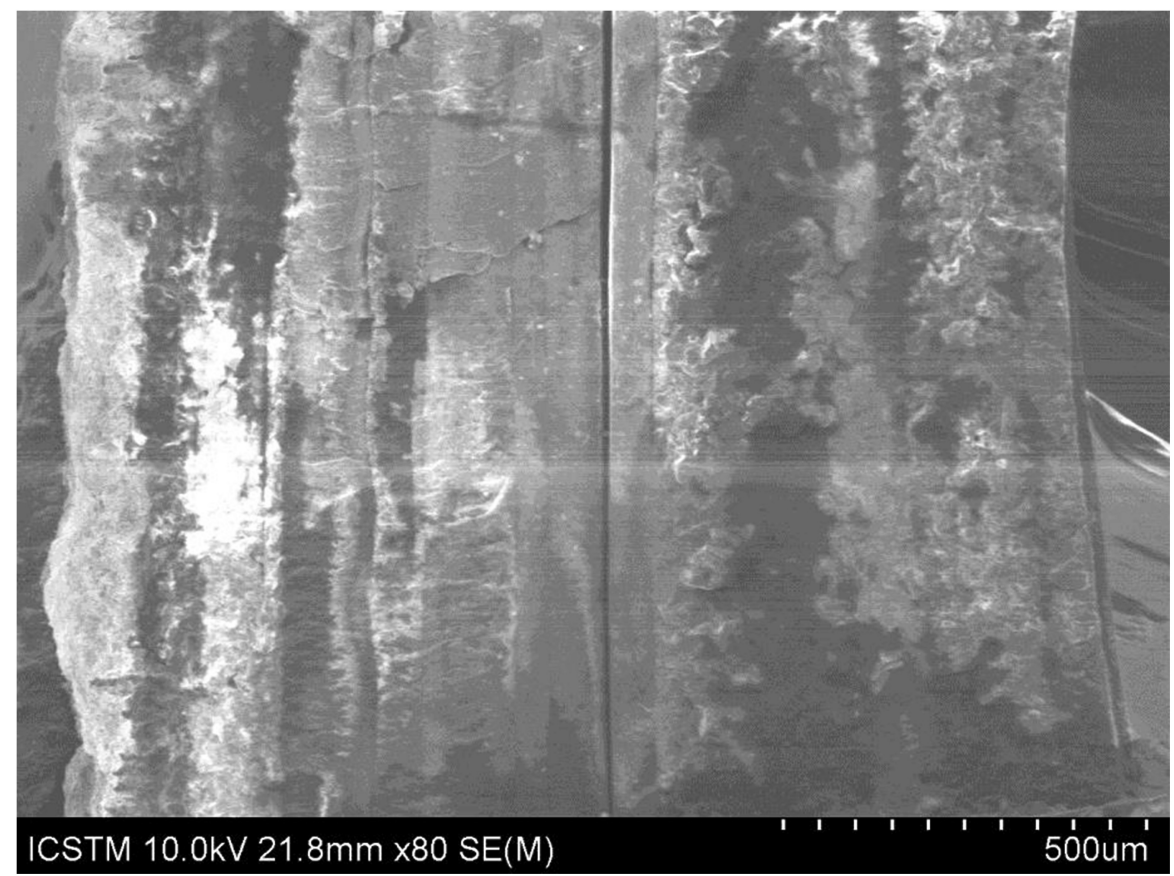

Fig. 4. SEM images of the analyzed stucco mortar

bonds, such as those originating from carbonates or carboxyl-groups of limestone. The most rich sulphate layers show the most intense band of $1700-1600 \mathrm{~cm}^{-1}$, and an increase of this band can be observed for the most degraded layer. Practically all layers show calcium sulphate, more intense as the most damaged, a sign that the degradation took time over each layer of plaster without cleaning the previous layer, Fig. 5.

Within the recorded spectra of all seven clay samples presented a weak absorbance centered on $3600-3700 \mathrm{~cm}^{-1}$ which can be attributed to hydroxyl vibrations.

According with the spectral data for both category of samples it can be concluded that the chemical composition of the layers are is quite similar (hydroxyl, carbonyl and $\mathrm{SiO}_{4}$ groups) [10-14].

FTIR spectral data are in well compliance with EDS and SEM, Fig. 6.

Based on the partial results obtained, we assume that the masonry is made of carbonate stone, the plaster applied on the wall of the house is mostly of lime with the most likely binders of different nature (glue, clay, sand, etc.).

The green color identified at one of the layers is due to a natural green pigment that varies in shades and color compositions. The "green earth" pigment is a mixture of Fe, $\mathrm{Mg}, \mathrm{Al}, \mathrm{K}$ (mainly minerals such as celadonite and glauconite) [15]. 


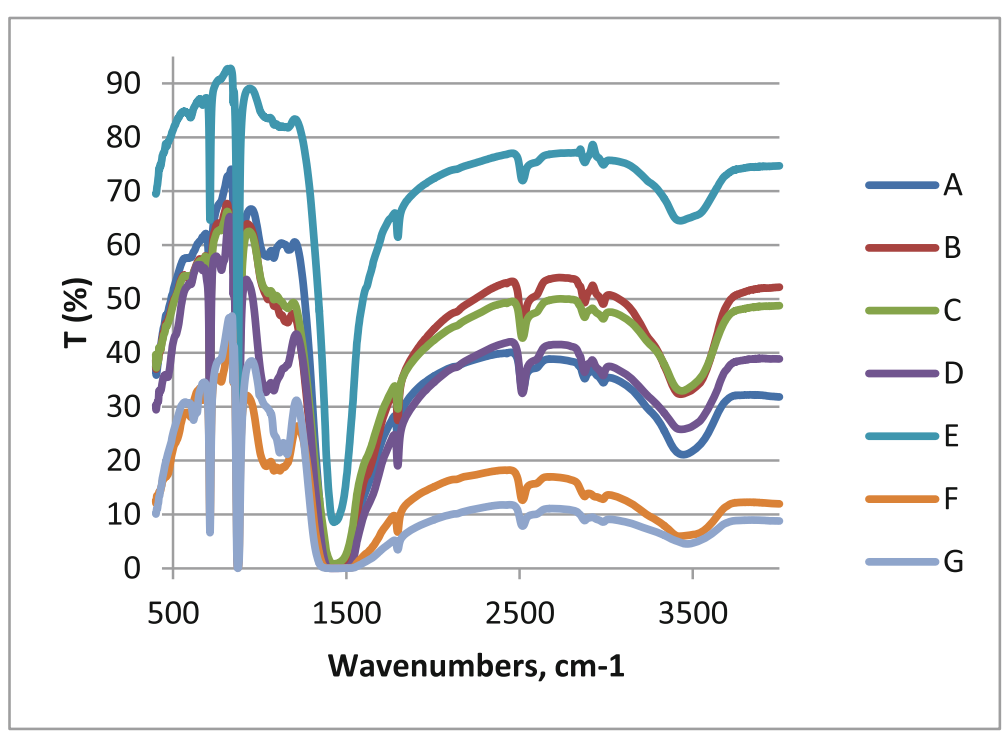

Fig. 5. FTIR spectra of the stucco's layers

The SEM images led to the following conclusions: the masonry layers from stucco sample present a lamellar structure, with a granular structure with lamellar inclusions as well. The first layer (the oldest one) shows a damaged structure, mostly due to the second layer applied, entirely based on gypsum, the most aggressive agent for masonries in general. The second layer shows a structure of aluminosilicates responsible for implosion, Fig. 6.

The presence of gypsum is major diminished in all the subsequent layers, and as other mortar layers have been applied over time, new elements specific to building materials that have emerged over time, such as barium sulfide or zinc or even chromium, as a component of some pigments (PG17 for example) [16].

EDS results (Fig. 7) have shown that with the exception of the layers I and II, where are predominant lime and gypsum, in all the other layers, C (40-60\%), O (20$25 \%), \mathrm{Zn}(30-50 \%)$ are the major constituents of the stucco's masonry sample, but also have been recorded elements as: $\mathrm{Ca}(0.14-3 \%), \mathrm{Mg}(1.23-1.61 \%)$, $\mathrm{Ti}(1-3.23 \%)$.

From elemental analysis through EDS, we can observe the presence of calcium, which leads us to the conclusion that the plaster is lime-based, and in some layers, especially those rich in zinc, a green dye may have been used, Fig. 6. 


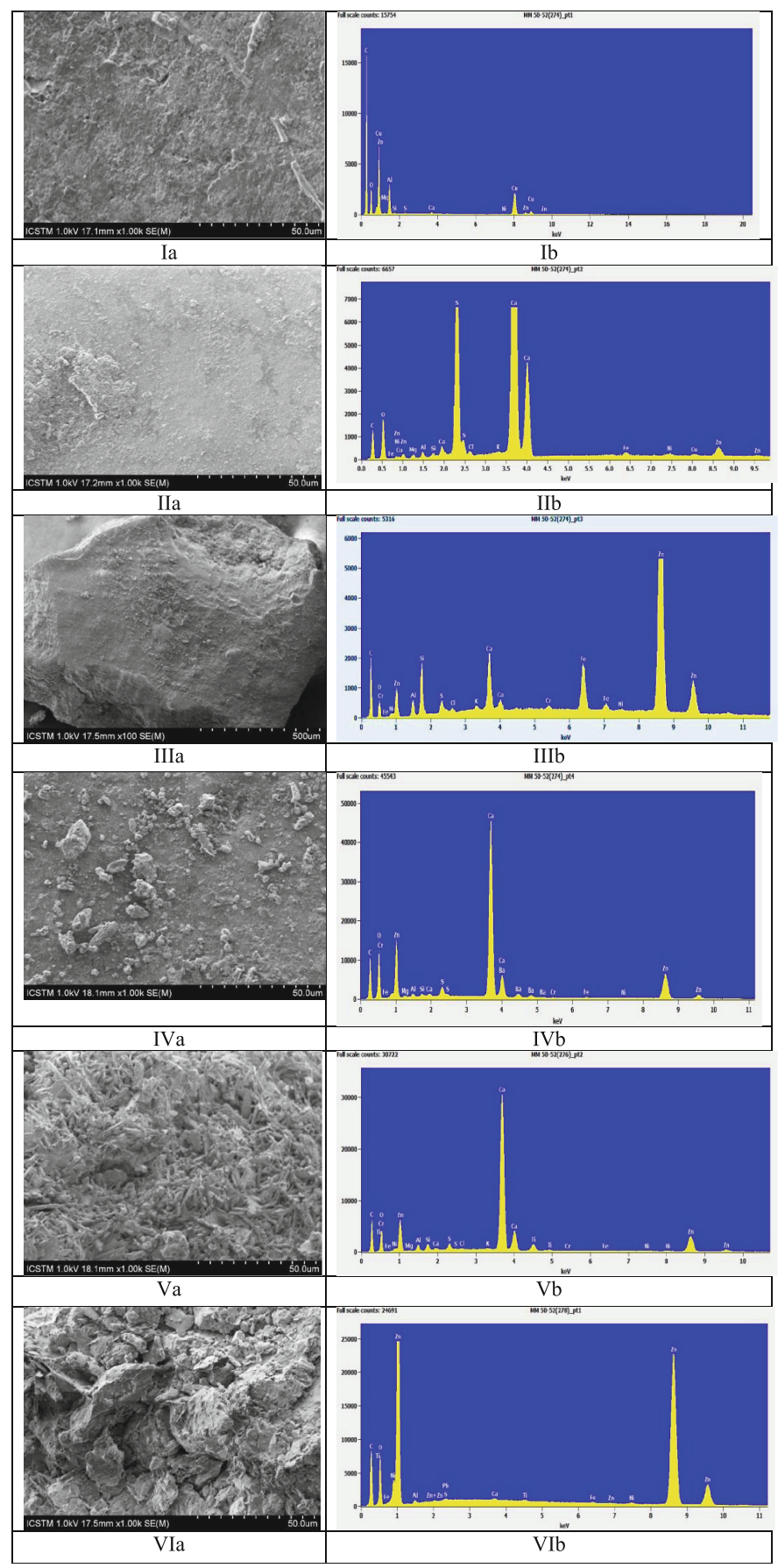

Fig. 6. The SEM images (left) and EDS diagrams for the studied samples (Color figure online) 


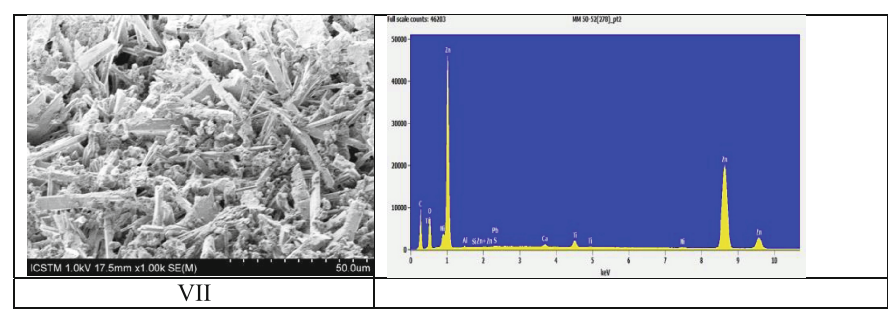

Fig. 6. (continued)

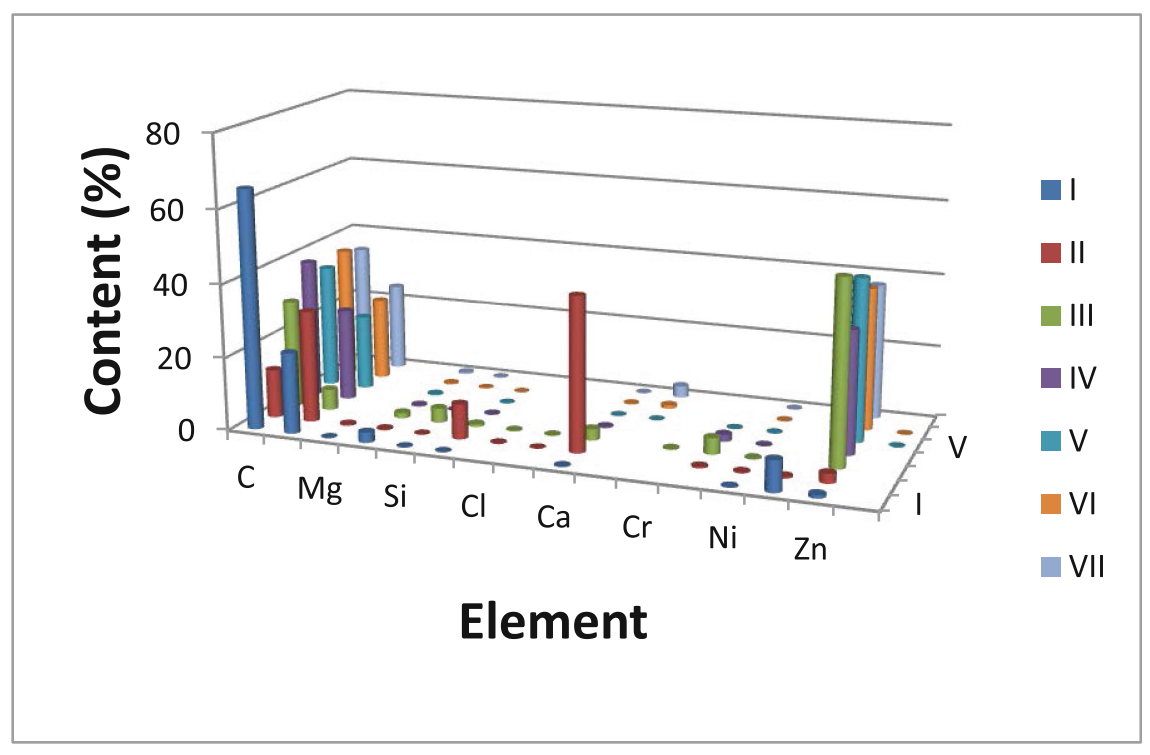

Fig. 7. The elements distribution from the stucco's layers

\section{Conclusions}

Despite the limited numbers of samples, the archaeometric results indicate that there is a obvious link between 3D scanning of the samples, in order to recover the initial shape, and to analyze the successive layers of the masonry applied in time.

Some of the local clay sources could have been considered the suitable raw material used for the restoration procedures in time. However, further determinations performed on a larger number of samples are needed in order to confirm this state of the research.

Acknowledgments. This work was supported by a grant of the Romanian National Authority for Scientific Research, MCI-UEFISCDI, project number 51PCCDI/2018. 


\section{References}

1. Ion, R.-M., Teodorescu, S., Bucurica, I.A., Ion, M.-L., Turcanu-Carutiu, D.: Restoration and preservation of cultural heritage monuments. digital presentation and practical solutions. Digit. Present. Preserv. Cult. Sci. Herit. 6, 107-116 (2016)

2. Ion, R.M., et al.: 3D-reconstruction of the complex stuccoes from patrimony buildings. Digit. Present. Preserv. Cult. Sci. Herit. 7, 107-112 (2017)

3. Addison, A.C., Alonzo, C.: The vanishing virtual: safeguarding heritage's endangered digital record. In: Kvan, T., Kalay, Y. (eds.) Proceedings of New Heritage: Beyond Verisimilitude, pp. 36-48. University of Hong Kong (2006)

4. Bosche, F., Haas, C.: Automated retrieval of 3D CAD model objects in construction range images. Autom. Constr. 17(4), 499-512 (2008)

5. Datta, S.: Digital reconstructions and the geometry of temple fragments. In: The Proceedings of the 2007 International Conference on Digital Applications in Cultural Heritage, Taiwan, pp. 443-452 (2001)

6. Fontana, R., Greco, M., Materazzi, M., Pampaloni, E., Pezzati, L., et al.: Three-dimensional modelling of statues: the Minerva of Arezzo. J. Cult. Herit. 3(4), 325-331 (2002)

7. Pieraccini, M., Guidi, G., Atzeni, C.: 3D digitizing of cultural heritage. J. Cult. Herit. 2(1), 63-70 (2001)

8. Shih, N.J., Wang, H.J., Lin, C.Y., Liau, C.Y.: 3D scan for the digital preservation of a historical temple in Taiwan. Adv. Eng. Softw. 38(7), 501-512 (2007)

9. Franzini, M., Leoni, L., Lezzerini, M.: A procedure for determining the chemical composition of binder and aggregate in ancient mortars: its application to mortars from some medieval buildings in Pisa. J. Cult. Herit. 1, 365-373 (2000)

10. Franzini, M., Leoni, L., Lezzerini, M., Sartori, M.: The mortar of the B Leaning Tower of Pisa: the product of a medieval technique for preparing high-strength mortars. Eur. J. Min. 12, 1151-1163 (2000)

11. Moropoulou, A., Bakolas, A., Bisbikou, K.: Investigation of the technology of historic mortars. J. Cult. Herit. 1, 45-58 (2000)

12. Jordá, J.D., et al.: Mineralogical analysis of ceramic tiles by FTIR: a quantitative attempt. App. Clay Sci. 115, 1-8 (2015)

13. De Benedetto, G.E., Laviano, R., Sabbatini, L., Zambonin, P.G.: Infrared spectroscopy in the mineralogical characterization of ancient pottery. J. Cult. Herit. 3(3), 177-186 (2002)

14. Chukanov, N.V.: Infrared Spectra of Mineral Species, vol. 1. Springer, Dordrecht (2014). https://doi.org/10.1007/978-94-007-7128-4

15. Antonelli, F., et al.: Multianalytical approach to diagnosis and conservation of building materials: the case of Punta Troia Castle in Marettimo (Aegadian Islands-Sicily, Italy). App. Phys. A 122(4), 1-10 (2016)

16. Bruno, P., et al.: Chemical-physical and mineralogical investigation on ancient mortars from the archaeological site of Monte Sannace (Bari-Southern Italy). Thermochim. Acta 418, 131-141 (2004) 
Open Access This chapter is licensed under the terms of the Creative Commons Attribution 4.0 International License (http://creativecommons.org/licenses/by/4.0/), which permits use, sharing, adaptation, distribution and reproduction in any medium or format, as long as you give appropriate credit to the original author(s) and the source, provide a link to the Creative Commons licence and indicate if changes were made.

The images or other third party material in this chapter are included in the chapter's Creative Commons licence, unless indicated otherwise in a credit line to the material. If material is not included in the chapter's Creative Commons licence and your intended use is not permitted by statutory regulation or exceeds the permitted use, you will need to obtain permission directly from the copyright holder.

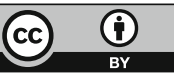

